\title{
Autogestión de los Trabajadores, una Experiencia en Expansión para Enfrentar el Desempleo Urbano: el Caso Argentino
}

\author{
Dr. Alejandro Rofman* \\ Lic. Inés Liliana García* \\ Arq. M aría di Loreto
}

Resumo: 0 objetivo deste trabalho éanalisar, com a necessária profundidade, a origem, o desenvolvimento, os propósitos e perspectivas de um processo de auto-gestão em pleno desenvolvimento na Argentina contemporânea: imposta pela "marcha" das empresas fechadas ou em situação judicial conflitante, que lhes impedia de funcionar, por seus antigos trabalhadores. Neste documento pretendemos descrever as distintas fases que tem atravessado asintenções de recuperação de empresas fechadas, evalorizar o novo modelo de gestão para ressaltar o diametral contraste com 0 que foi desenvolvido previamente.

Palavras Chave: Auto Gestão, Argentina, Desemprego Urbano

Resumen: El objetivo del trabajo consistió en analizar con la necesaria profundidad el origen, desarrollo, propósitos y perspectivas de un proceso de autogestión en pleno desarrollo en la Argentina contemporánea: la puesta en marcha por sus antiguos trabajadores de empresas cerradas o en situación judicial conflictiva, que les impedía funcionar. Pretendemos describirlas distintas fases que han ido atravesando losintentos de recuperación de empresas cerradas, así como valorar el nuevo modelo de gestión para resaltar su diametral contraste con el desarrollado previamente.

Palabras-clave: Autogestión, Argentina, Desempleo Urbano

* Doutor em Ciências Econômicas - Universidad de Córdoba, Coordenador do Programa "Sustentabilidad del Desarrollo Urbano - Centro de Estudios Urbanosy Regionales - Universidad de Buenos Aires, Argentina. E-mail: abrofman@ fibertel.com.ar

** Pesquisadora do Programa "Sustentabilidad del Desarrollo Urbano - Centro de Estudios Urbanos y Regionales - Universidad de Buenos Aires, Argentina. E-mail: ilgarcia@ uolsinectis.com.ar

*** Pesquisadora do Programa "Sustentabilidad del Desarrollo Urbano - Centro de Estudios Urbanos y Regionales - Universidad de Buenos Aires, Argentina. E-mail: mdiloreto@ ciudad.com.ar 


\section{Introducción general}

Las experiencias económicas populares son un desafío que individuos, grupos y comunidades están desarrollando para enfrentar latremenda exclusión social generada por el sistema económico dominante. Con ellas renacen aquellosviejos conceptosteóricostales como "solidaridad", "autogestión", "autonomía" que, absolutamenteopuestosal neoliberalismo padecido, ayudan a dar una respuesta creativa a las necesidades socialesy anhelar mejorescondiciones devida.

"el hecho de que miles de obreras y obreros, en diferentes lugares de Argentina y en otros países, recurran simultáneamentealosmismosmétodose ideas, demuestra la existencia de una conciencia histórica profunda, subyacente, escondida.(...) Es, por consiguiente, una idea y una práctica subversiva, que surgen siempre que el capitalismo sufre una aguda crisis, visible para todos, o cuando la dominación de una casta burocrática, que tiene métodos y valores capitalistas, pasa también por una crisis brutal que pone al desnudo su ilegitimidad". ${ }^{1}$

La formación de organizaciones de carácter económico asociativo respondeclaramenteal intento degenerar iniciativasy experiencias, adaptadas alasnuevascondiciones económico-políticas, a través de múltiples estrategias desobrevivencia, innovando viejas prácticas- tal como el cooperativismo - con importantes antecedentes delargatradición en el país. D esde el cooperativismo se quiere mostrar que una nueva sociedad puede crearsesin necesidad dequeel principal protagonista sea un Estado Absoluto - como eje detodo el proceso - ni, por supuesto, el mercado funcionando de forma libre.

El citado enfoqueapunta air estableciendo nuevas pautasorganizativasen el proceso deproducción y distribución delos bienes, quegaranticen otro reparto delosbeneficios, profundamentejusto y equitativo.

"Ellos y nosotros sabemos que lo único que genera riqueza y bienestar es el trabajo. Esto justifica que nos apropiemos de las máquinas y los espacios económicos que las patronales abandonan. Es nuestro derecho al trabajo para satisfacer nuestras necesidades el que fundamenta ese primer acto clasista de autogestión que es la decisión asamblearia de tomar la planta.(...). N osotros recuperamos nuestras fábricas mientras otros compañeros en los movimientos de desocupados reúnen sus fuerzas en los barrios, generan comedores, compras comunitarias, emprendimientos de producción de alimentos y vestido, cooperativas de vivienda, mutuales detrans-

\footnotetext{
${ }^{1}$ Almeyra, Guillermo. Diario La Jornada, México DF 7 de diciembre de 2003
} 
portey compra demedicamentos. Lossindicatoscombativos aportan su movilización y su estructura solidaria. Las asambleas de vecinos y barriadas se suman al apoyo"2.

Frenteala cesantíay al cierre delas unidadesproductivasqueimpiden alostrabajadoresconservar sus empleos, como se expresa precedentemente, surgelanecesidad de quesea la mismafuerza detrabajo queseorganicepararecuperar espacios de producción y trabajo.

En tal sentido estasiniciativasdesubsistencia son propositivas. Rompen laatomización impuesta política y económicamente, y en su funcionamiento recogen ciertas concepciones detrabajo humano, talescomo la necesidad departicipación, deapropiación delaspropias condiciones deexistencia, de desarrollo y crecimiento personal, desociabilidad.

En el agudo contexto de la explosión del desempleo y de la desocupación de larga duración, la primera respuestadelostrabajadoreshasido dedefensa delasfuentesdeocupación, tratando demantener activala producción, anteprocesos deconvocatoriadeacreedores queconducían inexorablementea laquiebradeesasunidades productivaso prestadoras de servicios, y a su desaparición como fuentedeempleo. Sabían que, en el mejor deloscasos, tendrían un cobro parcial - y muy a largo plazo - de salarios adeudados y una mínima indemnización queseeffumaría enseguida. Frentea estarealidad, muchostrabajadoresoptaron por la recuperación autogestionada dela empresa, adoptando mayoritariamentelaforma jurídica decooperativa detrabajo, reconocida por la Ley 20.337 de1973.

"En realidad, éstas son nuevas formas de lucha, de creatividad que han encontrado los trabajadores, ante un proceso de crisis profunda que superó los métodos tradicional es, los métodos históricos delucha... porquecuando una fábrica quiebra ¿a quién seleva a hacer paro?, a nadie. En una sociedad con tasas de desocupación moderadas del $2 \% \circ 4 \%$, cuando una empresa quiebra, uno hace un juicio, trata de cobrar y busca otro empleo, pero con estos índices de desocupación esimposible pensar en regresar al mundo del trabajo. Entonces, lo que nos queda es la desocupación, la marginalidad social, perder la cultura del trabajo, pero además la cultura de la obra social, del salario y con todo lo que eso implica... en la medida que se empezó a instalar el modelo neoliberal en Argentina tomó al desempleo como la variable de disciplinamiento y, paralelamente, con el aumento del desempleo creció el nivel de mortalidad de empresas" José Abelli, M ovimiento $\mathrm{N}$ acional de Empresas Recuperadas

${ }^{2}$ Mensaje de los trabajadores de empresas autogestionadasal Congreso dela CTA Equipo de Trabajo de Empresas Recuperadasen la FETIA-CTA 
Esesta capacidad depropuestay, por lo tanto, visión defuturo, la queestá presenteen las respuestasorganizativas ensayadas por la población, la queleotorgasentido y relevancia a las experienciasen desarrollo dela actualidad. Al margen delas debilidades, limitaciones y delatodavía escasa presenciacuantitativa, entrela totalidad dela población pauperizada.

$\mathrm{N}$ uestro trabajo estará orientado hacia el análisis delas prácticas sociales relacionadas con la recuperación deempresas por partedelos trabajadores para su autogestión, especialmente quienes han decidido - por convicción o porqueentendieron queeralaúnica "que nosquedaba"- conformar una Cooperativa deTrabajadores

D ichas experienciasno tienen un desarrollo lineal, ni armónico, dadas las dificultades y obstáculos que deben enfrentar parasu desarrollo en el marco dela profunda crisisque atraviesael paísy quecomprendelas dimensiones económica, políticay social. N o obstante, en todos los casossignifican un avance considerableen términos dedesarrollo, teniendo en cuentael punto departida: exclusión económica y social delos actorescomprendidos.

El avanceseverifica en varios sentidos: el nivel dela organización dela comunidad, el grado deconciencia de susparticipantes, los procesos deenseñanza-aprendizajequese generan, el alcance de metas colectivas, la construcción deun espacio derepresentación eidentidad y - lo que escentral - la contribución a la subsistencia diaria de todos sus miembros. Tal es experiencias requieren nuestraatención, análisisy contribución.

Seconsideró queel examen delos problemasy dificultades por lasqueatraviesan era un ejercicio indispensable para acceder a comprender quéposibilidades efectivastienen estas organizaciones desuperarlos, a través desu propiaacción o medianteal gún proceso de reorientación y búsqueda de nuevas perspectivas, y quiénes pueden cumplir un importante papel como apoyo.

\section{Origen y desarrollo de las empresas autogestionadas}

Como suele suceder con losfenómenos sociales que responden a las necesidades del desarrollo socioeconómico en las distintas coyunturas históricas, las cooperativas detrabajo ${ }^{3}$ surgieron en la Argentina antes de queexistiera una normatival legal quelas ampa-

\footnotetext{
3 "Las cooperativas de trabajo configuran una opción productiva en la que la categoría de trabajo asociado ocupa un lugar especial. "Se trata de una relación económica-asociativa que se traduce en: a) una empresa autónoma en la que el poder de decisión corresponde susasociados; b) un capital social yun número de miembros variables; c) la condición delosasociados en tanto trabajadores que controlan con igualdad de derechos, directa o indirectamente, la organización y la gestión de la empresa; d) la asignación de los excedentes netos de la cooperativa a los asociados, en razón del trabajo prestado por losmismos; e) un interésal capital si esqueexistey, f) la creación deun patrimonio común irrepartible.(...). La igualdad de derechos de los asociados, la relación de actividad, el reparto proporcional y la creación de un patrimonio común irrepartible son características específicas de cualquier
} 
raray encuadrara. Así, en tanto las primeras experiencias habrían surgido hacia 1884, su regulación autónoma recién ocurrecon la Ley 11.388 de 1926, con cuyo marco legal se constituyela primera cooperativa detrabajo en 1931, dedicada a la construcción - "La Edilicia" dePergamino - , una experiencia decortavida en la provincia deBuenosAires. En 1957 los registros dan cuenta de la existencia de 94 cooperativas de trabajo con aproximadamente 10.000 asociados. En la década del sesenta son conocidas las experiencias de las cooperativas de trabajo IM PA y CITA - actualmente con 136 y 70 trabajadores respectivamente - y la emblemática C ooperativa de Trabajo de C ampo $\mathrm{H}$ errera en el sector agropecuario, entreotras.

D esdelos años ochenta la repercusión dela crisiseconómica y su secuela dedesempleo origina el auge del cooperativismo detrabajo. Esta relación es bien marcada en la década del noventa, en la cual la cooperativa detrabajo apareceprogresivamentecomo el último recurso deprotección del empleo.

Un ejemplo másfrecuentedel origen delascooperativasautogestionadaspor trabajadores son las constituidasa partir delas ex empresas contratistas deYPF, en la destilería de LaPlata y en Gral. M oscón, en Salta, organizadas como cooperativasdetransportedecombustible, mantenimiento deinstalaciones, etc. D etodasmaneras, estoscasosson numéricamentereducidos, tanto en el número decooperativas como en la cantidad deasociados.

U na cantidad más significativa de cooperativas autogestionadas se origina por la terciarización de actividades hasta ese momento realizadas por el sector público, con trabajadores en relación dedependencia. $D$ entro deun esquema dereducción del gasto público y achicamiento del Estado, antela situación de cesantes estostrabajadores conforman cooperativas en actividades como mantenimiento y limpieza de instalaciones públicas-principalmenteedificiosmunicipales, hospitales, etc.-, servicios delimpieza de calles y paseos, plazasy jardines públicos.

organización cooperativa. La diferencia esencial radica en la relación que existe entreel grupo asociado yla empresa, ya que la actividad cooperativizada es el trabajo (...) La cooperativa vincula una asociación y una empresa cuyas características distintivas son la adhesión a un principio deno-dominación del capital, queconsisteen dar primacía a la gestión de servicio de sus miembrosy/o a la comunidad, a la actividad sobrela rentabilidad y a los derechos del individuo sobre los derechos de la propiedad. La adhesión a este principio se manifiesta en tres esferas: - la que relaciona poder y capital: cada asociado tiene el mismo poder cualquiera sea la parte del capital que detenta; - la deremuneración del capital: esvoluntaria y está precisamentelimitada por el estatuto dela empresa; - la deafectación delos excedentes: además de las limitacionesplanteadas a la remuneración del capital, una partedelos excedentes generados está afectada a una reserva irrepartible, propiedad colectiva de la empresa y, a ese título, inalienable". Vuotto, Mirta: "El desempeño organizacional del Cooperativismo de Trabajo", Centro de Estudios de Sociología del Trabajo, UBA, Fac. de Ciencias Económicas., 1999. 
El período 1995-99 está marcado por la "crisisdel tequila”. Estudiosrecientes muestran que“...másquepor las privatizaciones y reforma del sector público, la reducción de empleosurbanos parecehaber sido principalmenteconsecuencia de la reestructuración y concentración delas actividades de producción y distribución quetuvieron lugar en losañosnoventa, particularmenteen el sector industrial. Las conclusionesdeesteanálisis destacan laimportanciaqueha tenido la contracción del empleo del sector industrial en la evolución de la tasa deempleo global dela economía"4

Anteel cierrede empresas privadas-general mente como producto de la quiebra, en este período se constituye un conjunto importante de cooperativas autogestionadas, la mayor parte de las cuales continúa en funcionamiento. Se constituyela Cooperativa Industrial Argentina M etalúrgicaJ ulián M oreno (CIAM ), heredera del histórico complejo industrial SIAM D i Tella (1997) y el Frigorífico Yaguané, entre un grupo de alrededor demás demedio centenar de cooperativas detrabajo constituidasen esosaños.

Ya a mediados de 1999, la recuperación por partedesus trabaj adores de empresasen proceso de quiebra o cerradas aparece, progresivamente, como el último recurso de protección 0 , incluso, decreación deempleo.

Lo señalado hasta aquí en el ámbito del mercado de trabajo, unido a la crisis macroeconómica y, a partir de diciembre 2001, de la fenomenal crisis financiera y de gobernabilidad que conllevan al cuestionamiento generalizado por partede la sociedad delas instituciones del régimen neoliberal existente, son elementos quedeben ser considerados para precisar al conjunto defactoresquedieron origen al movimiento de cooperativas autogestionadas.

"en la década del '90 estas fueron las primeras experiencias como una alternativa a la desocupación; y se encontró en la figura de la cooperativa, digamos no sólo como una figurajurídica, sino además como una al ternativa de empresa de capital humano y no capital dinero... como empresas de personas y no de dinero. Y además son empresas democráticas: un socio, un voto; porque todo el mundo tiene derecho a elegir y a ser elegido y porque reparte igualitariamente las riquezas que nosotros mismos generamos.. digamos, nadie puede ganar más de 4 veces del que menos gana." José Abelli. M ovimiento $\mathrm{N}$ acional de Empresas Recuperadas.

Losejemplos exitososhan tenido un efecto demostrativo fundamental en la recreación denuevas experienciasy, debemos agregar, el efecto catal izador deorganizaciones

${ }^{4}$ R.Frenkel y M. Rozada: "Productividad y empleo en la apertura económica", OIT, 1999. 
muy activas en el apoyo a losmovimientos popularesque en el último decenio reivindicaban tierras, viviendas, alimentos, empleo, derechoshumanosy justicia; estas organizacionestenían la posibilidad de aportar equiposformadospor abogados, contadoresy demás profesionales identificados con la lucha social, y constituyeron - y siguen brindando - un aporte fundamental tanto en las discusiones por las formas organizativas como por su potencialidad.

M ás importante aún, el apoyo de estas organizaciones y profesionales comprometidostuvo un rol fundamental en losprimerospasosa dar, una vez ocupada la empresa, en las accionesinmediatas del día siguientea la ocupación, a fin delograr frenar el proceso dequiebra, evitar el desalojo dela unidad, lograr queel juzgado seavengaa la posibilidad dereconvertir la empresa parada y ponerla en manos desustrabajadores, y conseguir que losgobiernos provinciales y municipales tomen las medidas queposibiliten el resguardo dela cooperativa y la producción mediante gestión obrera.

Entreestasorganizacionesque están prestando un invalorableapoyo a lostrabajadoresdeempresas en recuperación, se destacan el equipo dela Pastoral Social dela D iócesis deAvellaneda y la cooperativa detrabajo I M PA, delargatrayectoria. Losexponentesmás destacados de las mismas presiden los dos movimientos nacionales que nuclean a la mayor cantidad de empresas recuperadas. $\mathrm{H}$ ablamos del M ovimiento $\mathrm{N}$ acional deFábricas Recuperadaspor losTrabajadores, presidido por el Dr. LuisC aro, y del M ovimiento $\mathrm{N}$ acional deEmpresas Recuperadas, que conduce Eduardo M urúa.

Ambos M ovimientos coinciden en quela conformación deC ooperativas deTrabajo esla mejor forma de organización para apropiarse de la fuente de producción y ponerla en funcionamiento. Tanto el M NER como el M NFRT (desprendimiento del M N ER), así como la FEN CO OTER enfatizan la vía cooperativa en formaamplia.

"N uestra lucha pasa a ser una ofensiva por el bienestar de nuestro pueblo a partir de la vigencia de la justicia como val or que rige las relaciones, en reemplazo de la gananciay la compraventa del trabajo como principios deorganización económica y social.(...) La modalidad cooperativa de autogestión es para nosotros un cambio social y cultural. Esto implica la superación del pensamiento dominante y requiere un proceso de aprendizaje a partir del trabajo que cada uno realiza en el proceso productivo o de servicios y de los conocimientos que emergen del mismo". Equipo de Trabajo de Empresas Recuperadas en la FETIA-CTA.

Sin embargo, esta vía no es excluyente. Como se afirma en el M N ER: "N osotros creemos, y esto deberíaser responsabilidad del IN AES (instituto $\mathrm{N}$ acional deAsociativismo y Economía Social), de quehay más de 100 empresas recuperadas en todo el país. Q ue no necesariamente, además, tieneque ser cooperativa. D igamos que nosotros decimos 
que la cooperativa es una instancia pero lo que más importa es la autogestión de los trabajadores, quepuedeser por propiedad participada, que puedeser por otras formas de expresión jurídica queno necesariamente debe ser la cooperativa” ${ }^{5}$

0 trosnúcleos como el Encuentro de Empresas 0 cupadasy en Lucha, tal el caso de Zanón (y otrora Bruckman, hoy constituida en Cooperativa), plantean otro tipo de salidapara la recuperación de sus empresas: la estatización delosmedios de producción y la organización delaproducción bajo el control obrero.

Es decir, hay una gran flexibilidad en cuanto las formas jurídicas, manteniendo el componentedeautogestión o participación obrera; incluso encontramosformasinnovativas, sin antecedentesen el país, como esla sociedad anónima en quelasaccioneso partedeellas continúan en manos delos antiguos dueñosy la gestión estáa cargo delos trabajadores.

EI M N ER tieneapoyo formal del Congreso delosTrabajadoresArgentinos(CTA), de APYM E ylasU niversidades; forma partedel M ovimiento $O$ brero Argentino y como tal se nutre de las experiencias de lucha de la clase trabajadora. Entre sus objetivos de lucha reclama "Ia necesidad de desarrollar y consolidar la IndustriaA Argentina en el marco deun Proyecto $\mathrm{N}$ acional queponga la economíaal servicio delafelicidad del pueblo, teniendo al hombre como origen, actor y fin de la actividad económica". Tanto el M N ER como el M N FRT tienen como susprincipalesobjetivosluchar, por un lado, por la modificación de la Ley deQ uiebras, a fin deque el trabajo sea considerado como un bien social, y toda unidad productiva que cierra sea otorgada a sus trabajadores. Por otro lado, lograr la creación de un Fondo Fiduciario que surja del aporte de las Empresas Recuperadas que se encuentren en mejor condición económicay deaportes del Estado $\mathrm{N}$ acional para constituir capital detrabajo para las empresas recuperadas que comienzan a desarrollarse.

En el caso deFEN CO OTER, sobrela cual lamentablementetenemos escasa información, es más antigua. La cooperativa quelo lideraesel Frigorífico Yaguané-con cerca de500 asociados- recuperado por los trabajadores después de un largo proceso, en la segunda mitad dela década pasada. C on el énfasis puesto en la autogestión obrera y en la flexibilidad delasformasjurídicas, la FEN C O O TER seha desarrollado con fuerte apadrinamiento del gobierno, principal mente del delaProvincia deBuenosAires

El Encuentro $\mathrm{N}$ acional deEmpresas $\mathrm{O}$ cupadas y en Lucha realizó su Primer Plenario el 24 deagosto de2002, en Grissinópoli. En el mismo establecieron susprincipiosy objetivosdelucha:

- Expropiación de los activos y su entrega gratuita a los trabajadores en un plazo no mayor a 30 días;

${ }^{5}$ Entrevista realizada por nuestro equipo a José Abelli, 10 de septiembre de 2002. 
- Las deudas deben ser asumidas por los dueños, quienes deben responder con susbienes y patrimonio personal;

- O torgamiento deun subsidio no reintegrable, quepermitaa lostrabajadorescontar con el capital de trabajo necesario para hacer arrancar el proceso deproducción;

- Transformación detodas lasfábricasen manosdelostrabajadoresen proveedores privilegiados del Estado, demodo quelos productoselaboradosen ellassirvan paraabastecer las necesidades dehospitales, escuelas, asistencia social, vivienday otrasáreas públicas.

Las propuestas de este movimiento - fuertemente ligado a las organizaciones de desocupados: BloquePiquetero N acional, Barrios dePie, CoordinadoraAníbal Verón difieren delos restantesmovimientos en lo referido específicamente, como ya dijimos, a la vía deorganización dela recuperación delas empresas (estatización con control obrero versuscooperativas detrabajo y expropiación transitoria).

D etodasmaneras, si bien señalamosestas diferentes perspectivasen la orientación de los procesos derecuperación del trabajo a través denuevosmodelos desolidaridad social, también sedebe remarcar queno son posicionesirreconciliablesy queen el andar, en el accionar antela situación concreta deocupación dela empresa, en lasdiscusionescon los trabajadores delas plantas, en las distintas y acuciantes gestionesque se deben promover a fin de impulsar la quiebra, la puesta en marcha nuevamentedela unidad productiva, etc., lostrabajadores y organizaciones, más alládesu tendencia, actúan solidariamente. ${ }^{6}$

\section{Organizaciones sociales que acompañan a los trabajadores en su proceso de recuperación y autogestión}

La solidaridad activa, tanto para mantener la sobrevivencia del grupo como para posibilitar la puestaen producción delaunidad, provienebásicamente, decíamos, delas cooperativas que están en una lucha similar y de los movimientos nacional es que las agrupan, principalmenteel M N ER, el M N FRT y otras asociaciones detrabajadoresen situaciones similares: laFederación $\mathrm{N}$ acional deC ooperativas deTrabajo deEmpresas Reconvertidas (FEN CO OTER), el Encuentro de Empresas 0 cupadas y en Lucha, (Zanón) y laFEN C O O TRA, contribuyen a la prosecución deestasiniciativas. Así, por ejemplo, una de las cooperativas que constituyen el M NER posibilitó, mediante un

\footnotetext{
${ }^{6}$ El Segundo Encuentro del Movimiento Nacional de Empresas Recuperadas, celebrado en la Cooperativa Unión y Fuerza, Avellaneda, el 2/11/2002, contó con la presencia y adhesión de los representantes de Brukman, quienes finalmente en la actualidad constituyen una Cooperativa de Trabajadores, luego de una larga lucha por la estatización de la Empresa textil.
} 
préstamo a pagar alargo plazo, la reinstalación delos servicios eléctricosy deteléfono, de una de las empresas en lucha.

En muchísimoscasos, lasolidaridad proviene, también, delasorganizacionesbarriales o deal gunasinstituciones universitariastales como laU niversidad Tecnológica $\mathrm{N}$ acional, laU niversidad deBuenosAireso laU niversidad $\mathrm{N}$ acional deRosario, entre otras. Estas organizaciones son las quea través de asesoramiento legal en primer término, así como contable, económico-financiero, degestión, y en algunos casos de aspectostécnicos de producción, han contribuido sin duda a la construcción deuna salida solidaria antecada situación planteada.

No esajeno a estamovilización social afavor delostrabajadores deempresas recuperadas el apoyo recibido de las distintas corrientes depiqueterosy dela $C$ entral deTrabajadoresArgentinos (CTA), del FrenteN acional Contra la Pobreza (Frenapo), presentes en distintos momentos de este proceso, apoyando a los trabajadores de las empresas recuperadas.

El sindicalismo tradicional, en poco y nada se ha comprometido con estos movimientos, salvo laU O M deLaM atanza.

\section{Características generales de las Empresas Recuperadas}

El actual movimiento deempresas autogestionadastieneunadinámicamuy grande Si bien la información es incompleta y cuesta mantenerla al día, se puede estimar que las nuevas empresas recuperadas por lostrabajadores, según nuestros registros, son unas 159 y decimosqueestenúmero vaen ascenso puesto queanadieseleescapa, sencillamentepor la lectura dediarios, quecada semana apareceun nuevo fenómeno deestetipo.

Al ser cada caso un fenómeno espontáneo, querequieredeuna seriedepasos quese irán suscitando según sea la real idad desde la que parte, las empresas recuperadas en realidad están siempre en recuperación. Algunas están a la espera de que se decretela quiebra, otras que sele reconozca la constitución como cooperativa, otras de obtener materias primas para empezar a funcionar, al gunas producen y otras - a pesar de los intentos- por diversas razonesquedan en el camino. Ello hacequeno sepueda constituir un registro exacto decasos; el transcurrir del tiempo genera cambiostan aceleradosquelo que hoy podemos afirmar, mañana queda desactualizado.

$\mathrm{N}$ uestra base de datos fue construida con información brindada por la Central de TrabajadoresArgentinos, el M ovimiento $\mathrm{N}$ acional deEmpresas Recuperadas, el M ovimiento N acional deFábricas Recuperadas por losTrabajadores, artículosy noticias publicadasen diferentes medios de comunicación gráficos, consultas directas alas cooperativas, y fuede mucho valor la base de datos que constantementeactualiza el Instituto del 
Conurbano, dependiente dela U niversidad N acional de General Sarmiento, quenos permitió cotejar y ajustar nuestros datos.

$D$ ado que se trata de mantener y desarrollar fuentes de trabajo que se gestaron en un anterior modelo, no debesorprendernosquelamayor cantidad decasosestén emplazadosen

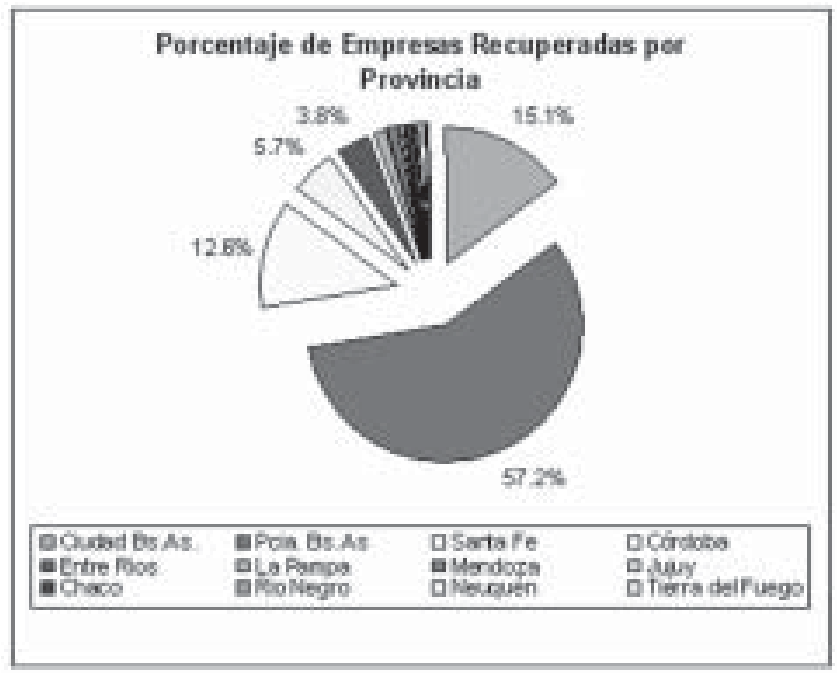

las provinciasqueconcentraron la actividad económica industrial. El 79\% deloscasosperteneceal sector secundario dela economía, es decir, elaboración deproductosmanufacturados.

Sin embargo, en esteúltimo año han crecido las empresas recuperadas destinadasa brindar servicios, tal escomo lasvinculadasal transporte, la salud o al área dela gastronomía; el sector terciario está representado, según nuestrosregistros, por el 14.5\% deloscasos. Sólo un $4.5 \%$ correspondea actividadesvinculadas con el sector primario dela economía.

D entro del sector industrial, la rama más frecuenteesla “metalmecánica” incluyendo fundición, fabricación de estructuras y caños, autopartes, etc. Es uno de los sectores productivos que ha experimentado fuertementela crisis del decenio, lo que ha conducido a la desaparición de una buena parte de estas unidades productivas. El $46 \%$ de las fábricas recuperadas se refieren a dicho rubro. Las cooperativas destinadas a la elaboración y procesamiento dealimentos concentran un $30 \%$ dentro de dicho sector, siendo los frigoríficos grandes concentradores de puestos de trabajo y, al mismo tiempo, en la industria dealimentostambién encontramos muchos casos de cooperativas pequeñas, en 
cuanto a la cantidad de asociadosque la componen. Por otro lado, deacuerdo a nuestros registros, la industria textil y la gráfica- imprenta concentran cada una un 10\% delas cooperativas industriales conformadas.

En cuanto a la localización del total de las empresas recuperadas, hay una fuerte relación con ladistribución según el tipo deactividad y, como esobvio, con la composición y radicación del modelo económico precedente. La mayor cantidad decasos están en laProvincia deBuenos Aires. Analizados según la localidad, observamosqueel $78 \%$ de los mismos pertenecen a partidos del Gran Buenos Aires, mientras que el resto se distribuye en diferenteslocalidades del interior provincial. En la Ciudad Autónoma de BuenosAires, las empresas anal izadas están básicamente en los barrios de la zonas sur y central, losmás dedicadosa industria y servicios

N euquen, Río N egro, Tierra del Fuego, en la Patagonia, suman apenasel 2\% sobre el total decasos. Pesea ello, losescasos establecimientosocupan un número importante de puestos de trabajo. Tal es el caso de Zanón en N euquen (310) o la Cooperativa Renacer AuroraU shuaia, en Tierra del Fuego (500), que es la empresa recuperada con mayor cantidad detrabajadores.

Podemosestimar quela cantidad de trabajadores queseencuentran vinculados con el proceso de recuperación deempresases de al rededor de 9000.

En todos los casos se inicia un largo y sacrificado proceso para los trabajadores que luchan por mantener susfuentes deingreso y las deotrostrabajadoresque, indirectamente, dependen delasanteriores- trabajadores deempresas proveedoras, distribuidoras, etc..

"Acá prácticamente nadie había tenido experiencia previa en autogestión o algo por el estilo". Esta frase, con idénticas o similares palabras, fue repetida en todas las entrevistas real izadas.

Lasfuerzas de seguridad suelen aparecen con orden de desalojo, situación que es rechazada por cuanto dicho desalojo es solicitado por la instancia judicial o por expropietariosqueavizoran una nueva posibilidad detrabajo, pero queimplica perder la oportunidad de recuperar el empleo por parte de los trabajadores desocupados.

La iniciativa autogestionaria surge de la confluencia de un conjunto de factorese iniciativas presentes en los análisis y discusiones queseplantean desde los primeros días de permanencia en la empresa: ¿y ahora cómo se sigue?, ¿qué alternativas jurídicas y empresariales se abren?, ¿cómo poner la planta en producción?.

"Y los problemas del después es que nosotros un día nos acostamos siendo trabajadores y nos levantamos una mañana siendo desocupados, y nos levantamos a la mañana siguiente siendo trabajadores pero además teniendo quehacernos cargo de la gestión empresarial... entonces, no es fácil, nosotros no venimos de la teoría a la práctica, aquí nadie se propuso en una mesa de discusión estratégica 
"hagamos la cooperativa"; en realidad surgimos de la práctica y bueno, estamos tratando de armar la teoría entre todos, lo cual es un camino difícil, que requiere de mucha discusión y de mucha paciencia". José Abelli, M N ER.

En los casos más frecuentes deempresas paradas, cerradaso en proceso de convocatoria, lostrabajadores seencuentran en una nueva situación en que poner en funcionamiento nuevamentelaunidad productiva; la resolución de esta problemática está exclusivamente en sus manos y, de manera inmediata, deben resolver cómo asegurar jurídicamente la apertura de la fuente de trabajo frentea una legislación adversa, que desembocaba en laquiebra dela misma.

"La empresa ni siquiera había caído en quiebra, estaba en concurso preventivo, pero estaba cerrada. D e hecho el concurso no se iba a levantar y la quiebra caería en cuestión de días o meses, todos sabían el fin que iba a tener eso (...) Estamos tratando de capitalizarnos primero. Trabajamos a costos muy bajos, que son los costos queestá pagando el mercado ahora. Y ya te digo, vos para hacer un servicio no podés poner un valor agregado, como cuando vos haces la inversión con la materia prima. Los precios prácticamente los fija el mercado y bueno, es la lucha entre la oferta y la demanda. Tuvimos queir a buscar nuevos clientes quenos den el trabajo a façon". Asociado de Nueva San Remo Cooperativa de Trabajo ex Textil San Remo Ltda.

Como decíamos, el proceso queva desdela entrada y custodia dela infraestructura productiva por parte delos trabajadores, hasta la resolución jurídico-política, lainscripción de la cooperativa autogestionada, la resolución dela problemática financiera y el inicio de la producción, es largo y colmado de dificultades. En la experiencia de los últimosaños, el inicio dela producción o dela puesta a punto de la maquinaria, selogra después de 7 a 10 meses de ocupación y de negociaciones. Cada empresa tiene sus particularidades, no todas parten deuna misma situación ni requieren de las mismas soluciones. Las hay que requieren sólo dematerias primas para reiniciar la producción, otrasnecesitan reacondicionar lasmáquinas, otras reemplazar lasinstalaciones obsoletas; hay quienes tienen un nicho en el mercado y enseguida encuentran su lugar y buenos dividendosquepermiten obtener alos trabajadoresuna retribución sustantiva-incluso muy por encima de los salariosmedios del gremio - y lashay quelescuesta insertarsesin una reconversión.

Lasformasorganizativas quevan tomando las empresas recientementerecuperadas son diversas. U nos pocoscasostienen en su origen un acuerdo con losantiguos dueños, que participan bajo distintasfiguras; por ejemplo, lostrabajadoresautogestionadosacuerdan el pago deun canon mensual a lospropietariospor losinmueblesy lasmáquinas, como en el 
caso dela Cooperativa M etal Varela. En otros, como en laC ooperativa deTrabajo Q uímica del Sur, los gerentes se asociaron a los trabajadores acordando la cesión de facturas por cobrar por partedela patronal y éseessu capital detrabajo inicial. También seencuentran aquí los casos de participación accionaria de los ex dueños y gestión obrera, tal como Polimex y Aldo M aronese, quejurídicamentesiguen siendo una sociedad anónima.

En otros casos setrata deal ianzas estratégicas, al gunastemporales y otras de mayor tiempo, por ejemplo en Zanello, donde se constituyó una sociedad anónima (Pauny S.A.), en la cual lostrabajadorestienen el 33\% delas acciones, los concesionarios- que son los que aportaron el capital de trabajo - tienen el 33\%, otro 33\% lo tienen el personal jerárquico y el $1 \%$ el M unicipio de Las Varillas.

Cada vez con más frecuencia, la expropiación por partedel poder público evitó la quiebra de la unidad productiva y conduce a la cooperativización de la misma. Para alcanzar esta solución, hasido necesario un largo proceso delucha, demovilizaciones, de presencia activa de los trabajadores de las empresas en cuestión, unidos al esfuerzo de gran parte de las cooperativas solidarias, de las apoyaturas de distintas organizaciones sociales, gestionando antela justicia a fin de queno se concretela quiebray, simultáneamente, anteel poder político para lograr la expropiación y la cesión a la cooperativa que, por otra parte, seestaba constituyendo. Esteproceso llevó a los trabajadoresa movilizarse en la calle, frentea losjuzgados, en las respectivas legisl aturas y frecuentementeimplica situaciones de gran tensión entre los trabajadores y el poder público que concurría a desalojar la empresa, o a retirar materias primas o insumos quereclamaban los dueños ${ }^{7}$

"Si nos va bien, sería lindo que cuando nuestros hijos crezcan, y racionalicen más las cosas, sepan que hubo una lucha y que esto costó, costó horas de venir a hacer guardias, de frío, de no comer en la casa, de no saber como se iba a pagar la luz, las deudas y de a poco..." A sociado Empresa Cooperativa G helco.

\footnotetext{
${ }^{7}$ Tal es el caso de la Cooperativa Lavalán, en la cual, mientras los trabajadores y sus asesores gestionaban frenar la quiebra, se hace presente el personal del Juzgado con fuerzas de seguridad, a fin de retirar una gran cantidad de lana que estaba dispuesta para ser lavada, con el argumento que esa lana era propiedad de otra empresa: en realidad, los dueños del lavadero habían transferido dicha empresa a una nueva sociedad, seis meses antes de su presentación judicial de quiebra, para después entrar en concurso, quebrar y quedarse con la maquinaria e instalaciones del lavadero. En realidad, la nueva empresa no existía: era un galpón vacío con unas pocas máquinas, sin lasmínimasinstalaciones que requiere la actividad y estaba puesta a nombre depersonasinsolventes. Por otra parte, se demostró que la transferencia de todas las instalaciones, maquinaria, materia prima y personal a la nueva sociedad, tal como figuraba en el expediente de su constitución, nunca se había efectivizado. Este ejemplo de vaciamiento de la empresa previa a su quiebra ha sido verificado en otros casos, por ejemplo Unión y Fuerza, Metalúrgica LB, Cooperativa Vieytes, etc.
} 


\section{Las nuevas cooperativas de trabajo: su organización}

D ecimosque estamos ante "nuevas" cooperativas detrabajo porquesusmiembros enfatizan ciertos aspectos deconsolidación delo asociativo, delo colectivo y de lo solidario que difiere deun emprendimiento cooperativo pensado y proyectado con antelación. $\mathrm{N}$ adiepensaba en convertirseen cooperativistay, en la medida quetoman las riendas de la producción, también van aprendiendo lasnuevas reglas dejuego.

Así, por ejemplo, en la mayoría de los casos, todos sus miembros tienen el mismo ingreso; no hay diferencias salariales relacionadas con la función que se cumple en la empresa. Con frecuencia, lasfunciones deadministración, contables, decomercialización, etc., son desempeñadaspor los propiostrabajadores "manuales", debido a quelosanteriores técnicosespecializadosno han acompañado al resto desus ex compañeros detrabajo.

0 tro aspecto a señalar esquelas decisionessetoman en A samblea G eneral. Esteesel mecanismo frecuentementeobservado en todas las cooperativas consultadas; al gunas de ellas ni siquieratienen al formal "C onsejo deAdministración" quetoma las decisiones diarias; todas las decisiones son tomadas en A samblea y resueltas a mayoría de votos. El consejo deadministración es representativo delas decisiones de la asamblea, dado quela organización eshorizontal.

Lainmensa mayoría delos trabajadores entrevistados, antela posibilidad dequese desvirtúen los principios del cooperativismo sobre participación democrática y control social ve dicha situación como un riesgo real, toman reparos para queno suceda en sus ámbitosy están atentos a quela reproducción delos valoresindividualistas, o la imagen del patrón, no sereinstaleentreellos.

Contrarrestando lo anterior, notamos entrenuestrosentrevistados otro rasgo importante que hace a la solidaridad del grupo, y es que cuando hay problemas - escasa demanda, por ejemplo - no seechaa nadiesino quedisminuyen las horas de trabajo del conjunto. Asimismo, y a pesar dela limitación de capital detrabajo, estas cooperativas tienden a no endeudarse, a no tomar crédito, aún cuando éstees hasta ahora prácticamenteinexistente o inaccesible, dados los requisitos que establecen: antigüedad dela empresa, propiedades en garantía, etc. Recién en el mes de diciembre del 2003, el Gobierno N acional plantea una seriedemedidastendientesafinanciar y otorgar créditos exclusivamentea empresas recuperadas. D etodasmaneras existe una aversión al endeudamiento que proviene del ejemplo de otras cooperativas de mayor antigüedad que tienen una alta morosidad, lo cual traba sus aspiraciones dedesarrollo; terminan produciendo para pagar el crédito y no para obtener un mejor sustento para susfamilias.

A pesar de todo, en todas estas experiencias se está afianzando la convicción en el trabajo asociativo. Predomina el apoyo mutuo entrelos trabajadores-apoyo quea veces flaquea dadas las penurias que pasan las familias en losmeses iniciales, prácticamentesin 
cobrar másqueun seguro de desempleo miserableo "algo para viáticos"- y la solidaridad recibida deotras cooperativasy organizaciones sociales. Todos estos elementos contribuyen a valorar la acción colectiva por sobreel "sál vesequien pueda" delaideología neoliberal dominante en la última década y que impregnó a extensos sectores de la sociedad, incluyendo a los que experimentan los efectosmás destructivos del modelo.

La tarea no es simple: se trata deacondicionar la maquinaria que ha estado parada duranteun tiempo; recuperar los antiguos clientes y su confianza, muchos de los cuales han optado por otrafuentedeabastecimiento anteel cierredelaunidad; deconseguir los mínimosrecursos para sal dar deudas deelectricidad, gas, teléfono, a fin dehacer funcionar las máquinasy todo el circuito productivo; capacidad deelaborar los presupuestosy, básicamente, contar con un capital de trabajo queles permita hacer frentea la necesaria compra deinsumosy otros gastos previosala venta desu producción inicial.

En al gunoscasos, la posibilidad de poner la empresa en funcionamiento provino dela existencia de stock o de la terminación y entrega de un pedido que la patronal tenía pendiente. Estospequeñosfondoshan servido para poner en movimiento ala cooperativa.

D etodasmaneras, la falta decapital detrabajo esuna limitante que incluyea todas las cooperativas de trabajadores recientementeformadas; una solución transitoria ante esta situación esel trabajo "afaçon", en quela demanda adelanta ala cooperativael valor dela materia prima queésta necesita para producir el bien, es decir, venden su capacidad deproducción a quien aportalas materias primas. Esto les permite obtener un primer capital, que luego utilizan para comprar "per se" las materias primasy adueñarse detodo el proceso productivo y comercial.

La experiencia está demostrando que, con dificultades, los trabajadores van adquiriendo la capacidad de gestionar, de administrar su propia cooperativa; claro está, no es algo que exista desdeel principio, pero se adquiere con cierta rapidez.

La evidencia de que es posiblela gestión obrera está en el hecho dequevarias delas empresas autogestionadas están en condiciones deincorporar nuevosasociados, generalmentetambién ex trabajadoresqueno seincorporaron inicial mentey queno creyeron en las posibilidades cooperativas, como en el caso delas C. deT. U nión y Fuerza, U nión Papelera Platense, entreotras. M uchos trabajadoreshan logrado másquecuadruplicar sus retirosmensual esoriginales-en Q uímica del Sur están retirando (según datosdeaño 2002) \$500 mensuales más alimentos, en U nión y Fuerza, más de \$1000-, y están prácticamenteen condiciones de comprar la quiebra y pasar a ser dueños definitivos de lasinstalaciones.

0 tro dato quees preciso evaluar es las edadesdelos socios. En su mayoría superan los 40 años, es decir, que dehabersesuprimido susfuentes de trabajo difícilmentehubieran podido insertarse en el mercado de trabajo formal. 


\section{La participación del sector público}

Tanto la C onstitución $\mathrm{N}$ acional como las provinciales y de la Cuidad de Buenos Aires tienen distintosarticulados coincidentes en la defensa delas fuentes de trabajo y se atienen a los conveniosinternacionales ratificados, considerando las recomendaciones de la O IT de "generar políticas y emprendimientos destinadosala creación deempleo..."

A pesar detoda esta legislación, en la década pasada cerraron miles de empresas y miles detrabajadoressetransformaron en desocupados. D urantetodala década del ' 90 , el Estado se marginó de cualquier acción que permitiera el salvataje de las unidades productivas y el mantenimiento delas fuentes detrabajo, aun teniendo lasherramientas legales para hacerlo

Recién antela caída del gobierno de D e La Rua, y antefuertesmovilizacionespopulares, algunasjurisdicciones reaccionan desempolvando leyes existentes-nunca aplicadasquelespermitían utilizar la causalidad de utilidad pública o de protección al trabajo, para intervenir en procesos dequiebra y posibilitar la continuación productiva en manosdelos trabajadores. No caben dudas de queen la actitud favorablea este tipo de resoluciones influyeron losfenómenospolíticos, financierosy deconflictividad social queseaceleraron a partir de diciembre de2001. Sin embargo, a pesar dela existencia de programas dentro lasSecretarías delaProducción, Empleo y D esarrollo Económico - existentesen el gobierno nacional y en prácticamentetodos los gobiernos provinciales y municipales-, éstasno contaban (y siguen del mismo modo) con másqueun escasísimo presupuesto, migajas dentro del presupuesto global. Como sostienen muchos trabajadores cooperativizados: "obtenésapoyo moral, asesoramiento, cursos...pero no seveun peso".

En las provincias dondeno se aplica la ley de expropiación, la situación es mucho más difícil. Por ejemplo, lostrabajadores del frigorífico Fricader -deG ral. Roca, provincia deRío N egro- hace 18 mesesquetienen tomadaslasinstalaciones. Esel único frigorífico lanar a $300 \mathrm{Km}$ a la redonda y por artilugios legales no es entregado a los trabajadores. Sostienen quecomo el Banco $\mathrm{N}$ ación es el principal acreedor hipotecario, el gobierno provincial no seanima a expropiar.

Con respecto al sector cooperativo tradicional, seencuentran desmanteladas las unidades públicas quetienen su accionar dirigido al sector. "A cá el Instituto N acional de Asociativismo y Economía Social esuna caja vacía que sólo da matrículas o que la Secretaría de la Pequeña y M ediana Empresa no disponga de créditos para bancar la producción...Eso quiere decir que el Estado no tiene políticas de empleo"8. EI IPAC (ex

${ }^{8}$ Entrevista al Sr. Abelli, Página/12, 13 de septiembre de 2002. 
Instituto Provincial de Acción Cooperativa) dela Provincia de BuenosAires ha sido desmantelado, eliminados sus programas de apoyo a las cooperativas, reducido a una D irección Provincial, con acciones exclusivas dematrícula.

En el ámbito de las actuales empresas autogestionadas - en particular, entre las adherentesal M ovimiento $\mathrm{N}$ acional deEmpresasRecuperadas y al M ovimiento $\mathrm{N}$ acional de Fábrica Recuperadas por los Trabajadores - existe la actitud de trabajar en conjunto con lasadministraciones públicas.

"Las cooperativas de trabajadores somos los socios ideales en la pelea del Estado por la empleabilidad. La gran ventaja de las cooperativas es que, asociadas con el Estado, privilegian la creación de empleo por sobre la acumulación de ganancias de los privados (...) En América Latina, y en particular en la Argentina, con el fracaso del fundamentalismo de mercado, han quedado en evidencia lo que en otras economías es una insinuación. Con ello quiero decir que están equivocados los que piensan que la autogestión de los trabajadores es un "fenómeno" de la crisis en Argentina. Lo que sucedeen Argentina esel preanuncio delas nuevasformas deluchas y organización de lostrabajadoresquese darán, inexorablemente, en el capitalismo. En laArgentina, los trabajadores de autogestión podemos constituir un 10\% de la población económicamenteactiva. Si tenemos en cuenta que en hay 5 millones dedesocupados y más de 100.000 establecimientos fabriles cerrados, como consecuencia de la ley de quiebras, hay posibilidad de recuperar en formainmediata 500.000 puestos detrabajo en forma directa y 300.000 en forma indirecta, lo que significaría inclusión, con base producción y trabajo, para 3 millones de argentinos. Si realizamos este análisis, la política de expropiación es absolutamente insuficiente. Pero para nosotros significa unagran conquistaconseguidacon lamovilización y lalucha”.) oséAbelli, M ovimiento N acional de Empresas Recuperadas.

También, dentro del ámbito $\mathrm{N}$ acional, en la segunda quincena de diciembre de 2003 fueron noticia diferentes políticas dirigidas al sector. U na tiene que ver con el crédito, dado quebajo el esquema vigenteel sector asociativo se encuentra excluido del financiamiento.

A nuestro entender, los anunciosno son más que políticas adecuadas al sector de cooperativasya en marcha; pero no incentivan la formación denuevas cooperativas ni sostienen a las más débiles

“Esta aparición por primera vez de líneas de crédito para las empresas recuperadas marca la clara institucionalización y el claro reconocimiento al esfuerzo, al trabajo, a la lucha desigual por recuperar del derrumbe a cientos de empresas que fueron en muchos casos vaciadas y con los métodos más viles fueron absolutamente descapitalizadas, dejando a cientos de trabajadores en la calle". 
Con estas palabras abrió el discurso el Presidentedela $\mathrm{N}$ ación tras ser anunciadaslas trespolíticas decrédito:

- La creación del Fondo de Asistencia a Empresas Recuperadas (Foempre), de seis millones depesos, coordinado por el BN A y lascarteras deTrabajo y D esarrollo Social. Los créditos de estefondo fiduciario serán de hasta 200 mil pesos, tendrán una tasa de 7 por ciento anual y serán sólo para capital de trabajo y activosfijos. Los que resulta novedoso y positivo es que, para acceder a ellos, será suficientecon quelas cooperativas presenten como garantía su proyecto detrabajo.

- Secreauna línea de C réditos del Banco $N$ ación para empresasqueestén en condiciones de acceder al crédito bancario. Préstamos para capital detrabajo, que se otorgarán por 50 mil pesos como máximo, con una tasa bonificada en un 30 por ciento y un plazo dedevolución dehastaun año. Por último,

- El Banco N ación cederá en forma deleasing (alquiler con opción a compra) loscréditos ehipotecas sobremaquinarias einmuebles defábricasqueno estén en uso, para que puedan ser reflotados por trabajadores. Sobre este punto, al menos para nuestras posibilidades, no hay demasiada información puesto que aún, nos indican, deben terminar decuadrar lasnormativas quelo pongan en funcionamiento.

El sector liderado por el D r. Luis C aro - M ovimiento N acional deFábricasRecuperadas por los Trabajadores- dio pleno apoyo a lasmedidas del PresidenteK irchner. No sucedió así con el M ovimiento $\mathrm{N}$ acional deEmpresas Recuperadas, su titular Eduardo M urúa decidió no participar del acto por considerar que "las medidas presentadaspor el G obierno son insuficientesy no representan una política pública clara parala recuperación del empleo"; pide "políticas más audaces" y advierteque "si hubiera políticas deEstado apoyando a lostrabajadores en una Argentina quetiene 65 por ciento dela capacidad instalada improductiva, sepodría reactivar sin lafamosainversión extranjera, y así impedir firmar acuerdos espurios con el FM I" ${ }^{\prime 9}$. EI M N ER pideuna ley de expropiación de unidades productivas - que garantice el acceso directo de los obreros a las empresas quebradas- y la cesión de créditos detodos los bancos oficiales.

El M inisterio deD esarrollo Social, a través dela D irección deE conomía Solidaria, ha lanzado el Programa deEmprendimientosProductivosSolidarios cuyos principales destinatarios son grupos de personas con iniciativas originadas en la autogestión, queformen parte de un proyecto comunitario vinculado a la producción de bienes y que

${ }^{9}$ Diario Página 12, 15 de diciembre de 2003 
presenten necesidades de apoyo en términos deasistenciafinanciera. A ellosseles brinda un subsidio no reintegrabledeun monto no superior a los $\$ 5.000$. C omo contraparte, deberán donar un porcentaje de lo producido a entidades intermedias que prestan servicios sociales en la comunidad.

Pero, tal vez, el programa que mayor trascendencia ha cobrado para el sector de empresas recuperadas es el Plan N acional "M anos a la O bra" que cuenta, entre sus objetivos el de "implementar un sistema masivo de apoyo a iniciativas de economía social", y entresus prestaciones de encuentra la deotorgar apoyo económico-financiero para la compradeinsumos, material es y equipamiento que se constituyan como capital detrabajo para los pequeños emprendimientos productivos. En el marco de dicho Plan - por medio de un subsidio de \$157.000 -, los 62 trabajadores de la Cooperativa Periodística y Gráfica deTrabajo, Consumo y Vivienda Limitada C O PEG RAF Ltda. adquieren en forma definitiva, dado que ganan la licitación, el periódico cordobés C omercio y Justicia. Se transforman aś, en el primer caso en queuna cooperativa queda en posesión de la empresa quese ha propuesto recuperar. Los trabajadores tuvieron que competir con un emprendimiento privado; sin embargo, las instalacionesfueron pagadascon losderechos que, como acreedores, tenían como personal dela firma en quiebra. Con el subsidio se podrámantener en funcionamiento la impresión y distribución de dicho periódico y de otros editadospor el mismo grupo.

Por otro lado, el Instituto N acional deAsociativismo y Economía Social (IN AES), también dependiente del M inisterio deD esarrollo Social, estátrabajando en un borrador quepermita gestar las bases de un Programa $\mathrm{N}$ acional deRecuperación deEmpresas, cuyo instrumento central será el aporte para un Proyecto de Ley que permita cubrir las actual esfalencias en losaspectos legal es, tecnológicosy de financiamiento.

En el Congreso dela $\mathrm{N}$ ación se han presentado dos proyectos de ley -aún no tratados- quebeneficiarían en gran medida a las empresas recuperadas: uno deellos, precisamente, esel Proyecto de Ley deFomento y Asistencia parala Recuperación deEmpresas por los Trabajadores, presentado por losdiputados CarlosR aimundi, Alberto Piccinini y $\mathrm{M}$ arcela Bordenave. En el artículo propone, $1^{\circ}$ : "la presente ley tiene por objeto la instrumentación de políticas de Estado tendientes a viabilizar normativa, técnica y financieramentelos procesos derecuperación deempresas en crisis, en quiebra o concursadas por partedesus trabajadores". Para ello se establecela creación del Fondo $\mathrm{N}$ acional parala Recuperación deEmpresas(FO N ARE), cuyas finalidadesabarcarían la cesión de créditos, otorgar apoyo técnico amplio y alentar acciones tendientes a impulsar la competitividad delas actividades productivas.

El presente proyecto de ley es sostenido por todoslosmovimientos de empresasy fábricas recuperadas y sus argumentos devienen de sus objetivos de lucha; pero su 
tratamiento quedó rel egado frentea un año de recambio electoral queantepuso la actividad particular o partidaria frentea la responsabilidad social dela mayoría delos congresistas. I gual suertecorreel Proyecto de Ley de Protección del Patrimonio Tecnológico, que presentaran los legisladores Francisco Gutiérrez, Fernando M elillo, M arcela Bordenave, M aría $\mathrm{O}$ caña y Alicia Gutiérrez, en el cual se daría respuesta definitiva ala serie deproblemáticasqueaquejan al desarrollo derecuperación de empresas.

Con el mismo espíritu, en noviembre de 2003 Eduardo M ondino, el defensor del Pueblo de la $\mathrm{N}$ ación, presentó ante el Congreso de la $\mathrm{N}$ ación y ante el Ejecutivo un proyecto de reforma dela L ey deC oncursos y $Q$ uiebras quebuscafavorecer la continuidad laboral delas empresas fallidas en manos de sustrabajadores. La propuesta tomala experiencia de 21 fábricas recuperadas y numerososfallosjudiciales en causas relacionadas con el cierre de empresas, de los cuales se recoge una serie de limitaciones de la legislación actual para que los magistrados puedan facilitar el mantenimiento de los puestos de trabajo y la actividad de las empresas.

En resumidas cuentas, si se busca un marco legal ( en al go se ha avanzado en este último año ) hay proyectos que responden alasnecesidades delas empresas recuperadas, proyectos quefueron forjados por los mismos trabajadores asociados y sus representantes. Pero hasta que no estén aprobados el vacío legal o el quedar a la espera dela interpretación de cadajuez, juega en contra del proceso de autogestión

Acaso, frenteala crisiscoyuntural y al planteo de unarespuestasoberana dereconstrucción de la economía ¿no sería mejor sancionar dichos proyectos antes que continuar emparchando un modelo que- haciendo agua por todoslossectores- postergaun desarrollo social genuino demejor generación y distribución dela riqueza? El desafío es político y, también, cultural. ¿Estarán dadas- en el presentegobierno (y en sustres poderes) - las condiciones para optar por una alternativa diferentedeconstrucción económico-social?; ¿será éstasu voluntad o simplementela de declamar y poner algunascuotas de progresismo dentro deun capitalismo decadente? Aquí están planteadas las diferencias deopinión que hoy guían a losmovimientos deempresaso fábricas recuperadas. M ásallá delosliderazgos, la diferencia está en la cuota de esperanza quesetenga: total, parcial o nula.

Si nosadentramosen la Ciudad deBuenosAires, nada resulta diferentealo acontecido en el ámbito nacional. La L egislatura de la Ciudad deBuenosAires, en la sesión del 1 deoctubre de 2003, aprobó la ley por la cual se estableceque, en caso detratarse de bienes deempresas fallidas sobre las cuales recaiga ley dedeclaración deU tilidad Pública, seentiendecomo valor objetivo el precio deventa posibleen rematejudicial. Esdecir, no se debetener en cuenta el val or demercado.

En esa misma sesión, se aprueba el Proyecto de Ley presentado por el Legislador Argüello, quetransfiere a las fábricas recuperadas las habilitaciones necesarias para la 
comercial ización desus productos. Setrata de los certificados y permisos que otorga la Dirección G eneral deH igieney Seguridad Alimentaria a distintos productospara que puedan ser comercializados en forma legal y se propone que, para todos los casos, los trámites para las habilitaciones se real icen sin costo alguno en sus sellados, timbrados, tasaso impuestos.

\section{Perspectivas y limitantes}

D ebetenerse presente que la constitución de cooperativas autogestionadas por los propiostrabajadoresantesituaciones dequiebra/cierredelaunidad productiva constituye un proceso largo, jurídicamente complejo en que los trabajadores deben enfrentarse normal mente a poderosos intereseseconómicos. La defensa de su fuentedetrabajo -que está garantizada por el articulo 14 y 14 bisdela Constitución $\mathrm{N}$ acional- esmediantela permanencia en el lugar de trabajo a fin deasegurar el traspaso detodas lasinstalaciones y maquinarias existentesa la cooperativa, particularmenteantelosfrecuentes procesos de quiebra, dondelos anteriores dueños pugnan por laliquidación en rematedela empresa, lo cual ha implicado frecuentes enfrentamientos con lasfuerzas de seguridad.

"N o sólo el contexto social y económico que da pie a la magnitud del fenómeno, sino el contexto político en el que las empresas recuperadas se insertan, tienen un papel protagónico y deben plantearse necesariamente la continuidad de su desarrollo.." 10

Interesa señal ar, aunqueestepunto requiere deun mayor desarrollo, el impacto que lanuevasituación macroeconómica tendría sobrela potenciación productiva-económica delas empresas recuperadas. Seadviertequecon la devaluación, automáticamente apa rece un conjunto muy importante de actividades que, gracias a la nueva paridad, se encuentran en condiciones desustituir importacionesy/o exportar. Pero a medida quese avanza en dicho proceso seadvierteque, másallá deun conjunto casi obvio deproductos donde la devaluación les ha ampliado sus ventajas naturales, en el resto se ponen de manifiesto limitaciones muy importantes para materializar sus potencialidades y que, hasta el momento, el Estado no ha tomado cabal partido por lasempresasautogestionadas.

“N osotros estamos tratando de instalar, en la agenda política, políticas públicas - políticas activas y proactivas - que tengan que ver con que el Estado, que en lugar de financiar al sector de la especulación financiera - porque acá no hay

\footnotetext{
${ }^{10}$ Informe del Relevamiento entre Empresas Recuperadas por los Trabajadores. Facultad de Filosofía y Letras. U. B. A
} 
ninguna posibilidad deinversión del sector formal, digamos: no vamosa tener un Plan M arshall, no van a venir los U \$S 120.000.000.000 que están en el extranjero y sabiendo que ningún capitalista va a invertir en producción en la Argentina en lospróximos años- busqueel camino por donde recuperar los activos productivos y recuperar los puestos de trabajo; levantar las persianas de las fábricas -que hay muchas que han sido destruidas por la apertura indiscriminada de la economíay nosotros creemos quepor ese camino podemos ll egar a recuperar hasta 1.000 .000 de puestos de trabajo en todo el país... si el Estado decide tener políticas sobre el sector." José Abelli, M N ER.

Entrelaslimitaciones comunes a todo tipo deempresa hemosencontrado: la restricción financiera, lano disponibilidad decapital detrabajo y la ausencia deprefinanciación para las exportaciones que acotan severamente la capacidad de reactivar sectores en condiciones dedar una respuesta rápida al incentivo cambiario; por otra parte, el esquema deconvertibilidad amplió la sustitución negativa deimportaciones. $D$ ado el tiempo transcurrido, esta capacidad productiva que se desactivó en los '90 seencuentra desmantelada u obsoleta. También hay que tener en cuenta la desarticulación verificada en la estructura industrial, lo que implica, entre otras limitantes, que una gran cantidad de insumos y bienes intermedios deben ser ahora importadosy son impactadosnegativamentesobrela devaluación.

Este conjunto de limitantes, ante un contexto macroeconómico potencialmente oportuno para la reconversión productiva y el crecimiento impacta en formamásnegativa en las nuevas cooperativas de trabajo, debido a que se encuentran sin capital de trabajo y en desventaja - frente al resto de empresas privadas - de conseguir crédito; vienen deun proceso deparalización productivay, frecuentemente, experimentan obsolescencia tecnológicay afrontan un fuerteproceso dereorganización empresarial al transformarse en cooperativas detrabajo.

Sin embargo, también a fines del presenteaño - másallá de las políticas públicas de crédito anunciadas por el ejecutivo - el D iputado N acional H éctor Polino logra quese apruebesu proyecto de L ey sobreC ajas de C réditos $C$ ooperativas, que presentara año tras año desdeel 2000. Esta Ley abre una enormeposibilidad de obtener créditos, independientemente delas políticas de estado. El cooperativismo de crédito esun movimiento económico y social quesurgió para dar acceso al crédito a los sectorespopulares habitualmentemarginados del circuito bancario y tieneunalargatrayectoria en todo el mundo. En nuestro país, las diversas dictadurasmilitaressehan ocupado dedesmantelarlo.

“El predominio de las doctrinas económicas del liberalismo, ha impedido desde la restauración de la democracia desarmar la herencia financiera de la última dictadura militar y permitir el reflorecimiento del cooperativismo decrédito. (...) 
H oy resulta imprescindible la caja de crédito local, manejada por los vecinos en cada pueblo del país, que haga accesible el crédito al pequeño industrial, comerciante, agricultor o asalariado. (...) I mpulsando su creación haremos realidad el progreso y el desarrollo independiente de nuestro país, al poner los dineros de los argentinos al servicio de la producción y del trabajo". Diputado H. Polino, gacetilla de prensa.

La Ley proponerestaurar la forma asociativa y, para ello, deja sentado que se exige la mutualidad rigurosa: todos losusuarios deberán ser asociados y sólo se permitela casa única; no permitela apertura defilial esen otras localidades en dondese pierdeel contacto directo entre vecinos. Las experiencias de autogestión pueden encontrar en dichas cajas de créditosel lugar ideal para financiar sus proyectoso ampliar sus horizontes.

El proceso derecuperación deempresasesmásquela mera acción dereactivar empresas cerradaso en vías deserlo; el trabajador toma contacto con otraformaderelaciones sociales, tanto dentro dela producción como en su vinculación con el afuera, cuestionándose a diario las desventajasqueencerraban paraél las relacionescapitalistasdeproducción.

"No sólo estamos manteniendo los puestos de trabajo sino contratando gente y superando los salarios establecidos en los convenios en la mayoría de las 15 empresas recuperadas [serefierealas delaCiudad deBuenos Aires]. (...) O bviamentereconozco que nos falta, pero estamos tratando de llevar el conocimiento de las universidades a las empresas recuperadas. El proceso no es fácil y más cuando se hace tan difícil podernos hacer cargo de las fábricas sin apoyo del Estado. D e todas maneras, no tengo dudas que una empresa recuperada va a resistir cualquier crisis mejor que una PyM e". Eduardo M urúa, Presidente del M N ER, diciembre de 2003.

\section{Conclusiones y demandas inmediatas}

El sal vatajedefuentesdetrabajo mediantelaautogestión delostrabajadoresconstituye un proceso muy dinámico. Lasdemandasinmediatas sehan concentrado en dosaspectos: la modificación delaactual Ley deC oncursosy Q uiebras, a fin de viabilizar jurídicamente un proceso quepermita el mantenimiento del patrimonio y los derechos depropiedad con sentido social para lostrabajadoresy no quedar a criterio del juez y delaprovinciadeturno. Y, luego, la necesaria consolidación del proyecto cooperativo medianteel apoyo crediticio y el reconocimiento como motor dinamizador deuna nueva economía.

Con respecto a lo primero, "La solución sería queno seliquiden los activos de las fábricas quebradas. Para esto pedimosuna modificación a la Ley deQ uiebras 24.552", sostiene Luis C aro, abogado y presidentedel M ovimiento $\mathrm{N}$ acional deFábricas Recuperadas por losTrabajadores. 
Lapropuestaessuspender por dosañoslaliquidación delafábricay cederlaen comodato a los trabajadores en cooperativa. "paralelamentesedeberían iniciar procesosindividuales deexpropiación. Con el pago delaindemnización cobrarían losacreedores. El valor sería mayor quesi se va a rematey no se destruyeel aparato productivo"11. "Si por la quiebra hubiéramos dejado quecerrara la fábrica detractoresZanello hoy no tendríamostractores en un paísqueproducealimentospara 300 millones depersonas", acotaAbelli, del M N ER. “Por quéno dictar una ley deemergencia que contemplesal var alasempresasen quiebra y transferir patrimonio al os trabajadores sobrela basedela deudaacumulada? El problema hoy esel privilegio delos bancosatravés dela hipoteca y la prenda. Pero ni a elloslessirve un clavo, porquese convierten en inmobiliarias, a pérdida". ${ }^{12}$

El otro aspecto serefierealanecesidad deconsolidar lasnuevasempresasautogestionadas “...no queremossólo hechos puntualessino políticas públicasque contemplen el problema del desempleo" y, como un ejemplo deéstas, el M ovimiento N acional deEmpresasRecuperadas propone "crear un fondo decapital detrabajo. Lostrabajadorestenemosel capital humano. Sabemos producir y administrar pero no tenemos dinero ni somos sujetos de crédito. Sin embargo quedó acreditado a través de 100 empresas y 10.000 puestos de trabajo que somos los únicos capaces de sostener empleo... Por eso, así como el Estado invierteen salud pública y educación, debeinvertir en trabajo"13

¿Q uéposibilidades deprofundizarsetienen estas experiencias? Pareceríaquela profunda crisisglobal en queseencuentranuestro país está dan do lugar ala emergencia de procesos innovadoresantesquearepetir experiencias pasadas quellevaron ala actual situación.

En este sentido, la experiencia de las cooperativas autogestionadas, de las formas asociativas de producción, distribución y consumo - como otros exponentes de la economía social - , aún con sus dificultades iniciales y la fal ta de apoyo global por partedel estado, están no sólo cuestionando el mal funcionamiento delo existente, sino queestán planteando una economía alternativa, con carácter social.

"Los trabajadores luego de haber sido financistas de los empleadores comienzan una nueva etapa que se maneja con una lógica económica distinta a la anterior. La lógica actual nos dice que para comenzar un proceso económico se debetener capital, luego invertir, producir, vender, luego pagar los servicios, insumos, impuestos, materia prima, retirar las utilidades, pagar los altos sueldos gerenciales y luego, de lo que

11 "Las cooperativas de trabajadores piden modificar la Ley de Quiebras". Diario El Cronista Comercial, 25 de septiembre de 2002.

${ }^{12}$ Entrevista al Sr. J. Abelli, Página/12, 13 de septiembre de 2002

${ }^{13}$ Entrevista al Sr. J. Abelli, Página/12, 13 de septiembre de 2002 
queda, se pagan salarios. Si no alcanza entonces comienza la etapa de reducción de salarios, suspensiones y cierre de la empresa. En las fábricas que recuperan los trabajadores la lógica es otra. Sefunda en unaeconomía básica desubsistencia. Por un lado, se obtiene el uso y goce de las instalaciones, maquinarias y herramientas, es decir, los M edios de Producción; por el otro, tenemos a los trabajadores que tienen la experienciade producir con esasmismas maquinarias por más de 20030 años. Este es un factor clave, ya que son ellos los únicos con posibilidades de hacerlo. Aquí se redescubre la importancia del trabajo y del trabajador en la etapa productiva. Ya no representa sólo un ínfimo salario, sino que adquiere su verdadero valor como sujeto del trabajo, como actor principal". Luis Caro, Presidente del M N FRT

Tanto esasí, quelasempresas recuperadasquieren mejorar suspolíticasproductivas, su tecnología, sus costosy generar másy nuevos productos. Están en plan dediseñar estrategias "para fortal ecer el desarrollo y la compeitividad delas empresas recuperadas, algo delo que carecen aunqueestén produciendo", señaló J oséA belli en laapertura del Encuentro celebrado en Rosario en diciembre de2003, con la presenciade 500 delegadosdeempresasrecuperadas, y representantesdeuniversidadespúblicasy organismosdeciencia y técnica.

El principal objetivo de dicho encuentro fue que del intercambio entre obreros, académicose investigadores surjan proyectos detrabajo conjunto quetengan aplicación concreta, y presionar entretodospor la implementación de políticas públicas quegaranticen la continuidad y el crecimiento de lasexperiencias deautogestión, como forma de recuperar puestos de trabajo y aportar a la producción nacional. Fruto deestedebateson los proyectos de lanzar una marca propia que unifique a las fábricas autogestionadas, mejorar la conexión entre sí para bajar costos y la mantener la política de reclamos al Estado, pero manteniendo su autonomía.

La instalación pública dela problemáticay su relación con el plano dela política es, entendemos, el aspecto quemás debemos reforzar. Las universidades deberían dar un enfoqueinterdisciplinario, el marco teórico, einvolucrarse en las acciones.

"Ya no alcanza con parches, ya no al canza con acciones reactivas, ya no alcanza con estrategias de sobrevivencia, éstas pueden tener éxito en al gunos casos y no tenerlo en otras, pero lo quees fundamental es que asumamos quela economía dejó de ser un hecho natural, o naturalizado, y que es posible construir otra economía, y que parte de ese proceso de construcción de otra economía implica comprender estas experiencias, conceptualizarlas y sobre todo conceptuar qué es la economía". ${ }^{14}$

\footnotetext{
${ }^{14}$ Coraggio, J.L exposición. Encuentro sobre aportes universitarios a las Empresas Recuperadas, UNGS, 12 de septiembre de 2003.
} 
Romper con la perspectiva de ver estas experiencias como una manera demantener puestos detrabajo, para tomarla como una al ternativa de economía social que puede reemplazar al sistema capitalista mismo, tal como seviene planteando en los diferentes encuentros del Foro Social M undial.

"planteamos (...) que hay que expandir el sistema de relaciones, y en particular del mercado de la economía social, ampliar la complejidad del sector de la economía social, generando más economía social y no viendo cómo se resuelve necesariamente el problema con el sector capitalista"15.

"Las empresas no son exclusivamente de propiedad privada, sino bienes sociales. Se construyen con mucho capital humano y el effuerzo de lostrabajadores", agregaEduardo M urúa, Presidentedel M N ER. Esteesel centro del debate, lareproducción y discusión en todo ámbito social, ayudaráa generar la concienciadequeotraalternativa puedeser posible.

Sobre esta al ternativa parecería abrirse un consenso cada vez más amplio. Así, por ejemplo, en uno delosúltimosencuentros del Plan Fénix, orientado a propuestasmás específicas y concretas deacción, se observa:

"En un segundo eje, seacordó queesteprograma redistributivo debeir acompañado de la acción sistemática, desde Estado y Sociedad, para dar organicidad, calidad y competitividad a un sector deeconomíasocial, con un régimen impositivo diferenciado, declarado de bien público, centrado en el trabajo, capaz de dar autonomía a los trabajadores al insertarse no sólo como consumidores sino como productores, y de poner otras condicionesal intercambio con los subsistemas dela economía públicay de la economía empresaria. La lógica de ese sector es la reproducción ampliada de la vida de todos y su desarrollo incluye introyectar los valores de equidad y de democracia participativa en el sector dela economía aública, através demecanismos depresupuesto participativo y de otras formas de corresponsabilidad por lo público entre Estado y Sociedad, y en el sector privado impulsando la cogestión y otros acuerdos más equitativos entre el trabajo y capital en lo que hace a los salarios y las condiciones de trabajo. Aquí seadvirtió la oportunidad queabren los procesos decrisisdeempresasquepueden ser reactivadas en basea estos acuerdos, delo cual yahay jemplosimportantes. Esteje implica pasar de políticas socialesasistencialistas, complemento dela políticaneoliberal, a políticas socioeconómicas y enmarcarlas en procesos de desarrollo local incluyentes de todos los ciudadanos". ${ }^{16}$ Plan Fénix, Comisión N ㅜ 5: Políticas sociales, laborales y de distribución. Facultad de CienciasEconómicas, UBA, mayo 2002.

\footnotetext{
${ }^{15}$ Coraggio, J.L exposición. Encuentro sobre aportes universitarios a las Empresas Recuperadas, UNGS, 12 de septiembre de 2003.

${ }^{16}$ Plan Fénix, Comisión №5: Políiticassociales, laboralesydedistribución. FacultaddeCienciasEconómicas, UBA mayo 2002.
} 


\section{Bibliografía}

ALM EYRA, G . Diario La J ornada, M éxico: 7 dediciembre de 2003.

BASU ALD O , E. Sistema Político y M odelos deAcumulación. U niversidad N acional de Q uilmes/FLACSO, 2001.

BAT TISTIN I, 0 et alli. La Atmosfera Incandescente. EscritosPolíti cossobrela Argentina M obilizada, CEILPIETTE, noviembrede 2002.

Centro de Estudios para el Desarrollo M etropolitano (CEDEM). La Industria $M$ anufacturera. Secretaría de D esarrollo Económico. G obierno dela Ciudad de BuenosAires.

CORAGGIO, J.L. LasEmpresasRecuperadasen el M arco dela Economía Social. Encuentro sobreaportesuniversitariosa lasEmpresasRecuperadas. U niversidad N acional G ral. Sarmiento, septiembre de 2003.

CORAG GIO , J.L. "U naAlternativa Socioeconómica N ecesaria: la Economía Social”. Ponencia presentada en el Seminario El Estado delasRelacionesL aboralesen la Argentina, N ueva Realidad Emergenteen el Contexto del M ERCO SU R, abril de 2003.

Equipo deTrabajo deEmpresas Recuperadasen laFETIA-CTA. M ensajedelosTrabajadores deEmpresasAutogestionadasal Congreso dela CTA. 2003.

Facultad deCienciasEconómicas delaU niversidad deBuenosAires. Plan Fénix, Comisón $n^{\circ}$ 5: Políticas Sociales, Laboralesy de Distribución. M ayo de 2002.

Facultad deFilosofíay Letras delaU niversidad deBuenosAires. Informedel Revamiento entreE mpresas Recuperadas por losTrabajadores. Programa Facultad Abierta, 2003.

FREN KEL, R y ROZADA, M . Productividad yEmpleo en la Apertura Económica. O IT, 1999.

KO RO L, C. "D ilemas del Cooperativismo en la Perspectiva deC reación dePoder Popular". Centro Cultural dela Cooperación. Cuaderno deTrabajo n²0, junio de2003.

KOSACO FF, B y RAM OS, A. Cambios contemporáneosen la estructura industrial argentina (1975-2000). U niversidad N acional deQ uilmes.

NEFFA, J. C. et alli. Exclusión Social en el M ercado deTrabajo: el Caso deArgentina O ITFundación Ford, D ocumento deTrabajo n ${ }^{\circ}$ 109, 1999.

O GAN D O , A. "Autogestión O breray Cooperativismo. Algunos Apuntes sobreel Caso delasFábricas 0 cupadas en Argentina", In: Revi stasTrabajadores, 2003.

OIT. Argentina, una D écada deC onvertibilidad, un Análisisdel C recimiento, el Empleoy la Distribución del Ingreso. 2002.

PALO M IN O , H. "Colapso Institucional y Reconstrucción Social en la Argentina”, In: Revista Latinoamericana deEstudiosdel Trabajo, Año 7, n 14, 2001. 
PALO M IN O , H . "LasExperiencias Actuales de Autogestión en Argentina. Entrela Informalidad y laEconomía Social", In: Revista N ueva Sociedad, n 184, 2003.

Revista en $\mathrm{M}$ archa. D ossier EmpresasC onducidaspor susTrabajadores. Abierto por Q uiebra. Año V, n²29, diciembre de 2002.

Revista en M archa. D ossier La Conquista del Espacio. Año VI, n 32, junio de 2003.

REZZÓ N ICO , A. "Empresas Recuperadas. Aspectos D octrinarios, Económicos y Legales". Centro Cultural dela Cooperación. Cuaderno deTrabajon n 16, marzo de 2003.

SAN C H A, J. Recuperación deFuentesdeTrabajoa partir dela Autogetión delosTrabajadores, Instituto deEstudiosy Formación Espacio deE conomía Social, CTA., julio 2003.

V ALLE, R. Autogestão o quefazer Q uando asFábricasFecham?. Rio de Janeiro: Sage/ Finep, 2002.

Vários Autores. Economia dosSetoresPopularesentrea Realidadeea U topia. Rio deJaneiro: Editora Vozes, Rio deJaneiro, 2000.

VU OTTO , M . EI D esempeño O rganizacional del Cooperativismo deTrabajo. Centro de Estudios de Sociología del Trabajo, U BA, Fac. deC iencias Económicas, 1999. 
Alejandro Rofman, Inés Liliana Garća e M aría di Loreto - Cadernos PRO LAM /U SP (ano 3 - vol. 1 - 2004), p. 67-95 